\title{
A new approach in compatibilization of the poly(lactic acid)/ thermoplastic starch (PLA/TPS) blends
}

\author{
Marzieh Akrami ${ }^{\text {, }}$ Ismaeil Ghasemi ${ }^{a}{ }^{*}$, Hamed Azizi ${ }^{a}$, Mohammad Karrabi ${ }^{a}$, \\ Mohammad Seyedabadi ${ }^{\text {b }}$ \\ a Processing Department, Iran Polymer and Petrochemical Institute, P.O. Box: 14965/115, Tehran, Iran \\ ${ }^{\mathrm{b}}$ Molecular Imaging Department, Persian Gulf Biomedical Sciences Research Institute, Bushehr University of Medical Sciences, P.0. Box: 7514633341, \\ Bushehr, Iran
}

\section{A R T I C L E I N F O}

\section{Article history:}

Received 22 August 2015

Received in revised form 26 January 2016

Accepted 11 February 2016

Available online 23 February 2016

\section{Keywords:}

Compatibilization

PLA/thermoplastic starch blend

Morphology

Mechanical properties

Biodegradability

\begin{abstract}
A B S T R A C T
In this study, a new compatibilizer was synthesized to improve the compatibility of the poly(lactic acid)/thermoplastic starch blends. The compatibilizer was based on maleic anhydride grafted polyethylene glycol grafted starch (mPEG-g-St), and was characterized using Fourier transform infrared spectroscopy (FTIR), dynamic mechanical thermal analysis (DMTA) and back titration techniques. The results indicated successful accomplishment of the designed reactions and formation of a starch cored structure with many connections to $\mathrm{m}$-PEG chains. To assess the performance of synthesized compatibilizer, several PLA/TPS blends were prepared using an internal mixer. Consequently, their morphology, dynamic-mechanical behavior, crystallization and mechanical properties were studied. The compatibilizer enhanced interfacial adhesion, possibly due to interaction between free end carboxylic acid groups of compatibilizer and active groups of TPS and PLA phases. In addition, biodegradability of the samples was evaluated by various methods consisting of weight loss, FTIR-ATR analysis and morphology. The results revealed no considerable effect of compatibilizer on biodegradability of samples.
\end{abstract}

(c) 2016 Elsevier Ltd. All rights reserved.

\section{Introduction}

In recent decades, biodegradable and renewable polymers have intensively attracted attention due to their huge influence on reducing the environmental pollution (Leja \& Lewandowicz, 2010; Siracusa, Rocculi, Romani, \& Rosa, 2008; Vroman \& Tighzert, 2009). Poly lactic acid (PLA) is one of the most important representatives of this category which is produced from natural resources such as corn, starch, sugar, etc. (Auras, Harte, \& Selke, 2004; Auras, Lim, Selke, \& Tsuji, 2011; Garlotta, 2002). PLA is linear thermoplastic polyester with stiffness, tensile strength and gas permeability comparable to those of synthetic polymers. However, low degradation rate, relatively high cost and high inherent brittleness are considered as limitations for its applications (Jamshidian, Tehrany, Imran, Jacquot, \& Desobry, 2010). Blending with other natural polymers (with higher degradation rate) is recommended to overcome the low degradation rate of PLA. Due to low cost, abundance and availability from different botanical resources (Tester \& Karkalas,

\footnotetext{
* Corresponding author.

E-mail address: I.Ghasemi@ippi.ac.ir (I. Ghasemi).
}

2001), starch can be a good candidate to increase the biodegradability of PLA (Lu, Xiao, \& Xu, 2009; Schwach \& Avérous, 2004). On the other hand, poor processability because of higher melting point compared to its decomposition temperature is the most important limiting factor for starch. In this regard, gelatinization with plasticizers such as glycerol (Lourdin, Bizot, \& Colonna, 1997; Poutanen \& Forssell, 1996; Stepto, 2003; Tang, Alavi, \& Herald, 2008), water (Hulleman, Janssen, \& Feil, 1998; Teixeira, Da Roz, Carvalho, \& Curvelo, 2007), urea (Ma, Yu, \& Wan,2006; Shogren, Swanson, \& Thompson, 1992), citric acid (Shi et al., 2007), sorbitol and other sugars (Poutanen \& Forssell, 1996) has been reported to enhance starch processability (Da Róz, Carvalho, Gandini, \& Curvelo, 2006) and the obtained compound is known as thermoplastic starch (TPS). During gelatinization, plasticizers destroy the hydrogen bonds between starch macromolecules, along with a partial depolymerization of starch backbone.

The main challenge for obtaining a blend based on PLA/TPS with suitable properties is the enhancement of interfacial adhesion between hydrophilic starch granules and hydrophobic PLA phases (Ke \& Sun, 2003; Kim, Chin, Yoon, \& Jung, 1998). Many efforts have been done to improve the compatibility in PLA/TPS blends using a variety of compatibilizers. Using PLA-g-MA as a compatibilizer for this binary blend has been reported by researches. It 
is believed that the reaction between anhydride groups of PLA-gMA and hydroxyl groups of starch can improve the interactions between two phases (Chapleau, Huneault, \& Li, 2007; Huneault \& Li, 2007; Li \& Huneault, 2011; Orozco, Brostow, Chonkaew, \& Lopez, 2009; Tachaphiboonsap \& Jarukumjorn, 2013).

According to literature, the next alternative compatibilizer for this system is isocyanates derivatives groups. Formation of urethane groups between isocyanate and $-\mathrm{OH}$ groups presented on both starch and PLA improves interfacial adhesion. The effects of a phenyl diisocyanate (PDI) compatibilizer on the properties of citric acid modified PLA/TPS blends has been studied and it was found that PDI increases homogeneity, improves particle size distribution, and enhances interfacial interaction in citric acid modified PLA/TPS blends (Karagoz \& Ozkoc, 2013; Ke \& Sun, 2003).

In this regard, Shi et al. (2011) reported significant improvement of mechanical properties including a decrease in the glass transition temperature in PLA and size reduction of the TPS phase as a result of 10-15 wt.\% GPOE (glycidyl methacrylate grafted polyethylene octane).

Similarly, Polyethylene glycol (PEG) enhances interfacial interaction between TPS and PLA, and increases PLA crystallization because of plasticizing effect on PLA (Ferrarezi, de Oliveira Taipina, da Silva, \& do Carmo Gonçalves, 2013; Ping, Kejian, Mingyin, \& Meijuan, 2013). Other compatibilizers such as maleic anhydride (MA) (Wang, Yu, \& Ma, 2007; Zhang \& Sun, 2004), PLA-g-MTPS (Wootthikanokkhan et al., 2012), PLA-g-amylose (Schwach, Six, \& Avérous, 2008) have also been reported in literatures.

This work is motivated by current studies for the development of biodegradable polymers. In this study, a new type of compatibilizer was synthesized to enhance the interfacial adhesion of PLA/TPS blends. The structure of synthesized compatibilizer was based on grafting maleated PEG on the surface of starch. To assess the efficiency of the compatibilizer, different blends based on PLA/TPS (containing obtained compatibilizer) were prepared via melt mixing method. Influence of the compatibilizer on morphology, mechanical, thermal and biodegradability properties of compounds were studied and discussed in detail.

\section{Experimental}

\subsection{Materials}

PLA (3251D, density $1.24 \mathrm{~g} / \mathrm{cm}^{3}$, MFI $=30 \mathrm{~g} / 10$ min at $190^{\circ} \mathrm{C}$ ) was supplied by NatureWorks (U.S.A) as a semi-crystalline grade. The corn starch was obtained from Mahshad Company (Yazd, Iran) and TGA measurements showed that the water content of starch was around $12 \%$. Glycerol (99\% purity), MA (density $1.48 \mathrm{~g} / \mathrm{cm}^{3}, 99 \%$ ), and PEG2000 were supplied by Merck Co.

\subsection{Synthesis of compatibilizer}

Synthesis of the compatibilizer was accomplished in two steps. At first, the grafting reaction between MA and PEG (MA/PEG $4: 40 \mathrm{w} / \mathrm{w}$ ratio) was done by melt mixing in a flask at $130^{\circ} \mathrm{C}$ with $2 \mathrm{~h}$ agitation. Starch particles (56wt.\%) were added to the mixture of PEG and MA at the second step, and reaction was continued for another $2 \mathrm{~h}$ at $150^{\circ} \mathrm{C}$. A proper quantity of toluene was added to reduce the viscosity. The moisture content of starch and the produced water during reaction was removed by isotropic distillation with toluene. The pasty product was cooled to room temperature, and samples were immersed in dimethylsulfoxide (DMSO) for $24 \mathrm{~h}$ at room temperature followed by centrifugation at $7500 \mathrm{rpm}$ for $15 \mathrm{~min}$ to remove the unreacted materials. The insoluble materials were dried in a vacuum oven for $24 \mathrm{~h}$ at $90^{\circ} \mathrm{C}$. To obtain samples of high purity, the above process was repeated
Table 1

Formulation of samples.

\begin{tabular}{lllll}
\hline Sample code & PLA (wt.\%) & TPS (wt.\%) & $\begin{array}{l}\text { Compatibilizer } \\
\text { mPEG-g-St (phr) }\end{array}$ & PEG (phr) \\
\hline Pure PLA & 70 & 30 & 0 & 0 \\
30T0C0P & 70 & 30 & 0 & 0 \\
30T5C0P & 70 & 30 & 5 & 0 \\
30T10C0P & 70 & 30 & 10 & 0 \\
30T15C0P & 70 & 30 & 15 & 0 \\
30T0C10P2000 & 70 & 30 & 0 & 10 \\
\hline
\end{tabular}

using ethanol as solvent. The obtained compatibilizer was labeled as $\mathrm{mPEG}-\mathrm{g}-\mathrm{St}$ in this study.

\subsection{Blends preparation}

At first, TPS was obtained by adding $25 \mathrm{wt} . \%$ glycerol to corn starch using an internal mixer (Brabender 55WTH, Germany) at $40 \mathrm{rpm}$ and $140{ }^{\circ} \mathrm{C}$ for $6 \mathrm{~min}$.

The obtained TPS was used in preparation of blend samples in the next step.

The blend samples were also prepared using Brabender mixer ( $60 \mathrm{rpm}, 180^{\circ} \mathrm{C}$, for $8 \mathrm{~min}$ ). In binary and tertiary blends, the TPS content was fixed at $30 \mathrm{wt} . \%$ and the mPEG-g-St content was $0-15$ wt.\% of total weight. A binary blend without compatibilizer (PLA/TPS) was also prepared for comparison. The composition and codes of samples are depicted in Table 1. As can be seen in Table 1, pure PLA was considered as standard sample. Finally, the samples were hot-pressed in a compression molding machine (Toyoseki, Japan) at $190^{\circ} \mathrm{C}$ and 25 bar for subsequent measurements. In the given codes, $\mathrm{C}$ and $\mathrm{P}$ denote the concentrations of compatibilizer and $P E G$ respectively and the number after $\mathrm{P}(2000)$ corresponds to PEG molecular weight.

\subsection{Measurements}

\subsubsection{Characterization}

Chemical structures of m-PEG and mPEG-g-St were examined using a Fourier transform infrared spectroscopy (Bruker, EQUINOX 55 ) over the wavenumbers ranging from 400 to $4000 \mathrm{~cm}^{-1}$. The sample for the FTIR experiment was prepared by a $\mathrm{KBr}$ disk method.

The presence of $-\mathrm{COOH}$ - groups in the m-PEG was evaluated using back titration technique according to Wootthikanokkhan et al. (2012).

At first, $0.5 \mathrm{~g}$ of the m-PEG was dissolved in $50 \mathrm{~mL}$ of ethanol, and mixed with $50 \mathrm{~mL}$ of an aqueous $\mathrm{NaOH}$ solution $(0.1 \mathrm{~mol} / \mathrm{L})$. The mixture was stirred until the homogeneous solution was obtained. Then, phenolphthalein was dropped into the solution and the solution was titrated with $0.1 \mathrm{~mol} / \mathrm{L}$ of $\mathrm{HCl}$ until reaching the end point (the solution turning from pink to colorless). Finally, acid number of the polymer sample was calculated using Eq. (1):

Acid number ( $\mathrm{mg} \mathrm{NaOH} / \mathrm{g}$ )

$$
=V_{\mathrm{NaOH}}(\mathrm{mL}) \times C_{\mathrm{NaOH}} \times 40 / \text { Polymer blend }(\mathrm{g})
$$

where $V_{\mathrm{NaOH}}=$ volume of sodium hydroxide solution $(\mathrm{mL})$ and $C_{\mathrm{NaOH}}=$ concentration of sodium hydroxide solution $(\mathrm{mol} / \mathrm{L})$

\subsubsection{Dynamic mechanical thermal analysis (DMTA)}

Glass transition temperatures of the samples were determined using dynamic mechanical thermal analysis by Tritec 2000 DMA instrument, Triton Technology, UK. The sample dimensions were $10 \times 30 \mathrm{~mm}^{2}$ in rectangular with a thickness of $1 \mathrm{~mm}$. The DMTA experiment was operated under a tension mode, at $1 \mathrm{~Hz}$ oscillating frequency, $1.0 \%$ static strain, $0.05 \%$ dynamic strain, and $10 \mathrm{~mm}$ amplitude. The used heating rate was $5{ }^{\circ} \mathrm{C} / \mathrm{min}$ and the samples were scanned over temperatures ranging between -100 to $130^{\circ} \mathrm{C}$. 
Tensile tests (Santam STM-20, Universal Test Machine) were performed at room temperature according to ASTM D638. At least five specimens were tested for each run and average values are reported.

\subsubsection{Morphology}

The morphology of the samples was examined by a scanning electron microscope (Tescan VEGA-II, XMU, Czech Republic). The SEM specimens were prepared from cryogenically fractured surface under liquid nitrogen. Extraction of the TPS phase in the binary blend was performed using $6 \mathrm{NHCl}$ at room temperature. The etched specimens were washed with distilled water before drying at $60^{\circ} \mathrm{C}$ for $24 \mathrm{~h}$. All samples were sputter coated with gold prior to observation. The SEM micrographs were processed with image analysis software (Image J) in order to obtain particle size distribution of TPS granules.

\subsubsection{Biodegradation test}

Biodegradability assessment of the samples was accomplished by buried in soil method. The soil consisted of composting microorganisms (PegahMilk Co., Tehran, Iran). The samples were kept at $30^{\circ} \mathrm{C}$ for 3 months. During the course of this testing, weight remaining was measured at two weeks intervals and the biodegradation rate was calculated as follows:

Weight loss $(\%)=\frac{M_{d}}{M_{0}} \times 100$

where $M_{d}$ is the remaining mass after degradation, $M_{0}$ is the original mass (dry) of the sample.

\subsubsection{Thermal analysis}

DSC analysis of PLA blends was carried out using NETZSCH200F3 Maia (Germany). For each measurement, the samples were heated to $200^{\circ} \mathrm{C}$, remained at this temperature for $5 \mathrm{~min}$, cooled down to room temperature, and reheated to $200^{\circ} \mathrm{C}$ (heating and cooling rates of $10^{\circ} \mathrm{C} / \mathrm{min}$ ). Crystallization and melting temperatures and crystallization percentage were obtained from DSC thermogram.

\section{Results and discussion}

\subsection{Characterization of synthesized compatibilizers}

As mentioned in the experimental section, preparation of the compatibilizer consisted of two steps: the production of $\mathrm{m}$-PEG and the reaction of $\mathrm{m}$-PEG with starch to produce $\mathrm{mPEG}$-g-St. Fig. 1 shows the FTIR spectra of PEG, MA and $\mathrm{m}$-PEG in specific stretching regions.

In Fig. 1, the PEG characteristic peaks are seen at $1114 \mathrm{~cm}^{-1}$ (C-O-C), a broad peak from 3200 to $3600 \mathrm{~cm}^{-1}$ (O-H stretching vibration) and peaks at $1349 \mathrm{~cm}^{-1}$ and $2888 \mathrm{~cm}^{-1}(\mathrm{C}-\mathrm{H})$, while the main characteristic peak for MA is at $1787 \mathrm{~cm}^{-1}$. After reaction between MA and PEG, a new peak appeared at $1643 \mathrm{~cm}^{-1}(C=C$ stretching vibration), indicating the opening of anhydride ring. Moreover, the presence of peaks at $1732 \mathrm{~cm}^{-1}(\mathrm{C}=0), 1126 \mathrm{~cm}^{-1}$ (C-O) and hydroxyl broad peaks at $3300-3600 \mathrm{~cm}^{-1}$ can be indicative of a reaction between PEG chains and MA resulting in the formation of $-\mathrm{COOH}$ groups at the end of PEG molecules. In addition, there is no peak at $1787 \mathrm{~cm}^{-1}$ corresponding to the ring anhydride carbonyl group, which implies a full reaction and opening of the MA ring. The formation of carboxylic groups at the end chains of PEG was also checked by back titration, and the results are depicted in Table 2. The acid number value of $\mathrm{m}$-PEG is higher than that of pure PEG which implies a successful reaction and the presence of $-\mathrm{COOH}$ groups on the PEG chains.

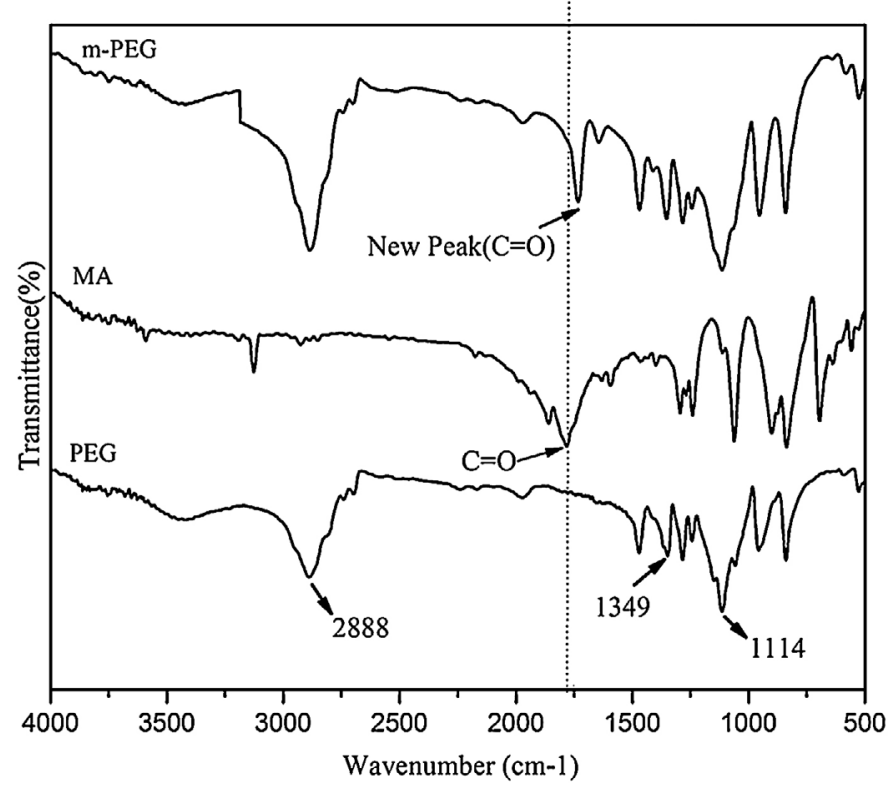

Fig. 1. FTIR spectra of PEG, MA, and m-PEG.

The FTIR spectrum of the synthesized compatibilizer as a product of the reaction between $\mathrm{m}$-PEG and starch is illustrated in Fig. 2a. In this spectrum, the ester bond can be realized by peaks at $1743 \mathrm{~cm}^{-1}$ (corresponding to $\mathrm{C}=\mathrm{O}$ stretching vibration) and peaks between $1000-1300 \mathrm{~cm}^{-1}$ (representing $\mathrm{C}-\mathrm{O}$ stretching vibration bond). The presence of these peaks confirms the reaction between m-PEG and starch. To confirm the aforesaid reaction, DMTA was also performed on synthesized compatibilizer and physical mixture of m-PEG/starch (Fig. 2b). In physical mixture of these components, two peaks were observed at -53 and $24^{\circ} \mathrm{C}$ which are related to $\mathrm{m}$-PEG and starch respectively. These peaks were shifted in synthesized compatibilizer to 4 and $35^{\circ} \mathrm{C}$ due to formed chemical bonds between m-PEG and hydroxyl groups of the starch. In other words, because of limitation in m-PEG movements by starch through chemical bonding the m-PEG related peak was shifted to higher temperatures.

Considering the accomplished reactions, the structure of final product is possibly consisted of a core of starch molecules with many connections to m-PEG chains (Fig. 3a). Regarding to this structure, pending chains including free carboxylic ends are capable of interaction with active groups of TPS and PLA phases. The probable reactions which can enhance interfacial adhesion and improve compatibility between polymeric phases are shown in Fig. $3 \mathrm{~b}$.

\subsection{The effect of compatibilizers on the properties of the blends}

To assess the efficiency of synthesized compatibilizers, the blend samples (based on PLA/TPS) were produced; then morphology, dynamic-mechanical behavior, crystallization and mechanical properties were studied.

\subsubsection{Morphology}

For the evaluation of polymeric blend systems, it is better to start by explaining the morphology because of its vital role in other

Table 2

Acid numbers of PEG and $\mathrm{m}-\mathrm{PEG}$.

\begin{tabular}{lll}
\hline Samples & $\mathrm{HCl}(\mathrm{ml})$ & Acid No. $(\mathrm{mgNaOH} / \mathrm{g})$ \\
\hline PEG & 28.7 & 170.4 \\
m-PEG & 19.6 & 243.2 \\
\hline
\end{tabular}


(A)

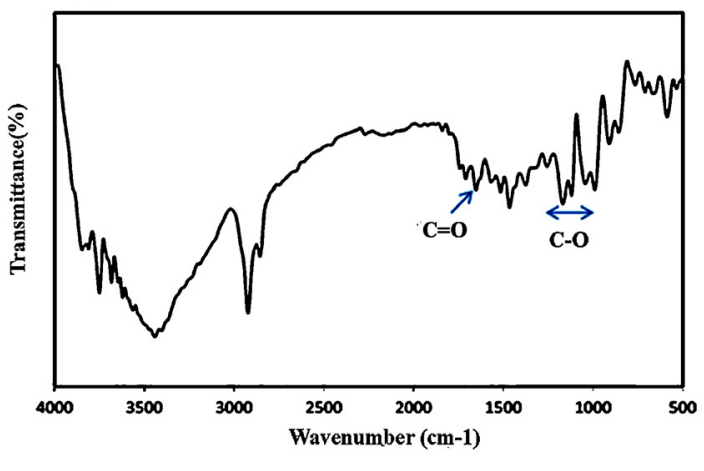

(B)

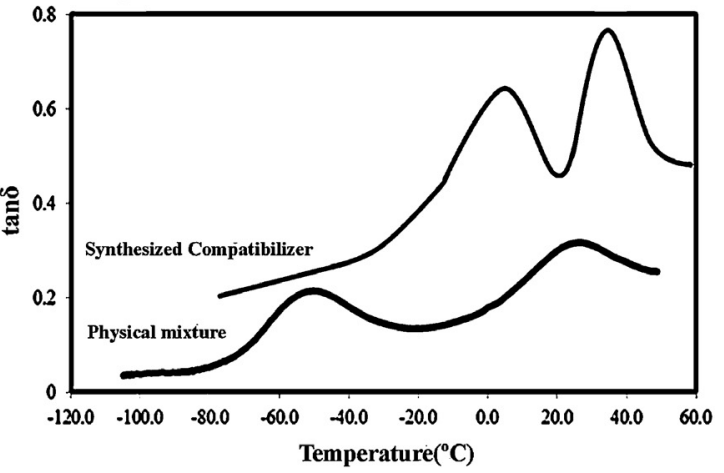

Fig. 2. (a) FTIR spectra of synthesized compatibilizer. (b) DMTA of synthesized compatibilizer and physical mixture of m-PEG and starch.<smiles>CCC1(COCCCC(C)(O)CCOC(=O)/C=C\C(=O)O)COC1(CC)COC(=O)/C=C\C(=O)O</smiles>

(I)

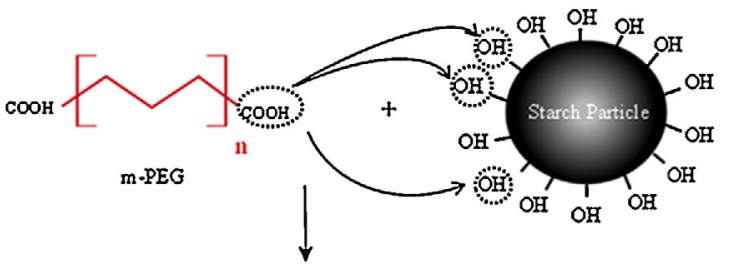

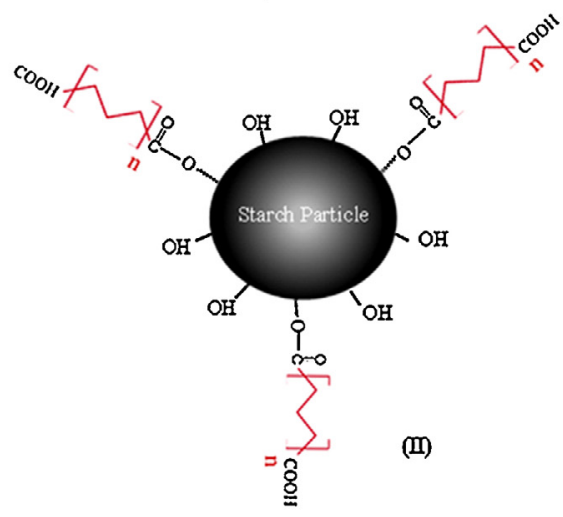

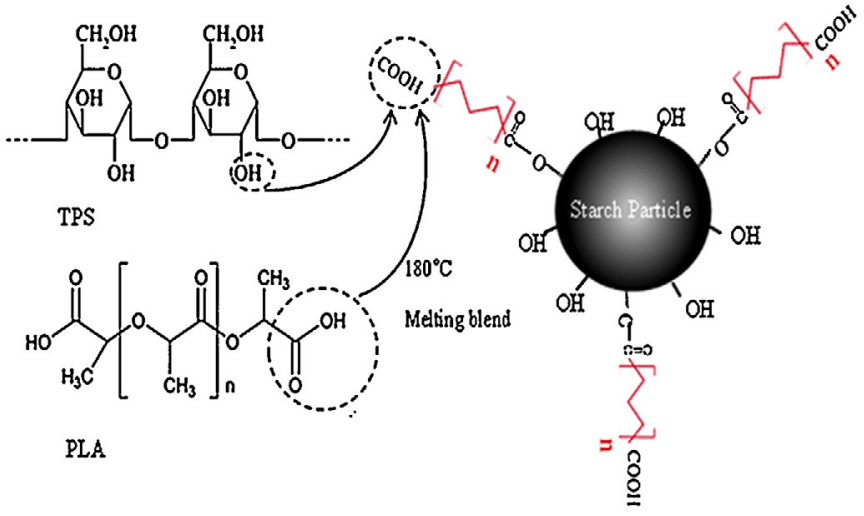

(b)

(a)

Fig. 3. Illustration of the synthesized compatibilizer: (a) end-capped reaction of PEG with MA; (b) hypothetical reaction of end-capped PEG and starch.

properties. Fig. 4 presents the SEM micrographs of the cryogenically fractured surface of the samples. TPS particles in 30T0COP sample were etched by $\mathrm{HCl}$ and black holes in the images are related to the extraction of these particles. In sample without compatibilizer, TPS particles were not uniformly dispersed in the matrix, and some agglomerates were detected (Fig. $4 a$ ). This can be due to the difference of hydrophilic nature of PLA and TPS phases. In Fig. 4b-d which correspond to the samples containing compatibilizers, the spherical particles were formed, and a better dispersion was obtained. This is possibly due to the improvement of interfacial adhesion between the two phases.

Particle size distribution of the dispersed phase was determined using image analyzer. For samples containing compatibilizer, the image analysis indicated that the range of dispersed phase size was between 10-19 $\mathrm{m}$ without considerable agglomerates (Fig. 4c).

\subsubsection{Dynamic-mechanical properties}

Dynamic-mechanical analysis is the most common methods for evaluation of the polymeric blend compatibility.

Temperature dependency of $\tan \delta$ for the samples is demonstrated in Fig. 5. According to literature, two distinct $\tan \delta_{\max }$ are observed for TPS: $\tan \delta_{\max }$ at $-40^{\circ} \mathrm{C}$ related to glycerol-rich phase and $\tan \delta_{\max }$ at $15^{\circ} \mathrm{C}$ corresponding to starch-rich phase (Teixeira et al., 2012). However, in this study the former $\tan \delta_{\max }$ was not observed. This may be attributable to low concentration of TPS in the compounds which is not able to respond in DMTA test 

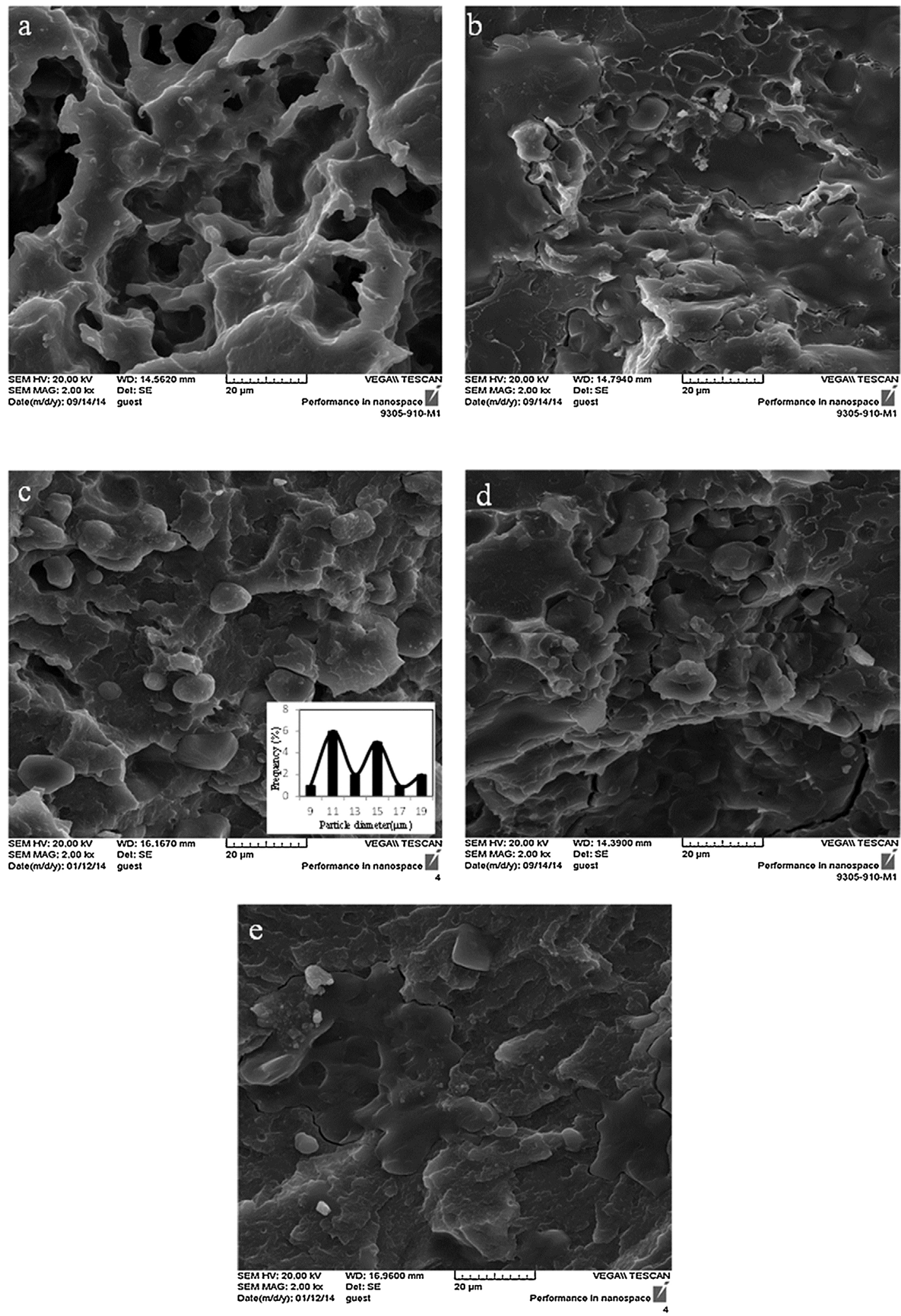

Fig. 4. SEM micrographs and particle size distribution histogram of (a) 30T0COP, (b) 30T5COP, (c) 30T10COP, (d) 30T15C0P and (e) 30T0C10P2000.

(Wang, Yu, \& Ma, 2007). In other hands, $\tan \delta_{\max }$ appeared at $65^{\circ} \mathrm{C}$ for PLA. The obtained results are summarized in Table 3. In this table, $\Delta T=\left(T_{1}-T_{2}\right)$; difference between two $\left.\tan \delta_{\max }\right)$ was calculated as an index of the compatibility of two phases. It is clear that reduction of $\Delta T$ implies the increase of compatibility.
The greatest reduction in $\Delta T$ was observed for the samples including $10 \mathrm{phr}$ of synthesized compatibilizer (30T10C0P) which can be a result of esterification between compatibilizer and TPS molecules and/or PLA chains. By comparing $T_{1}$ for the blends with neat TPS sample, the greatest reduction was observed for 


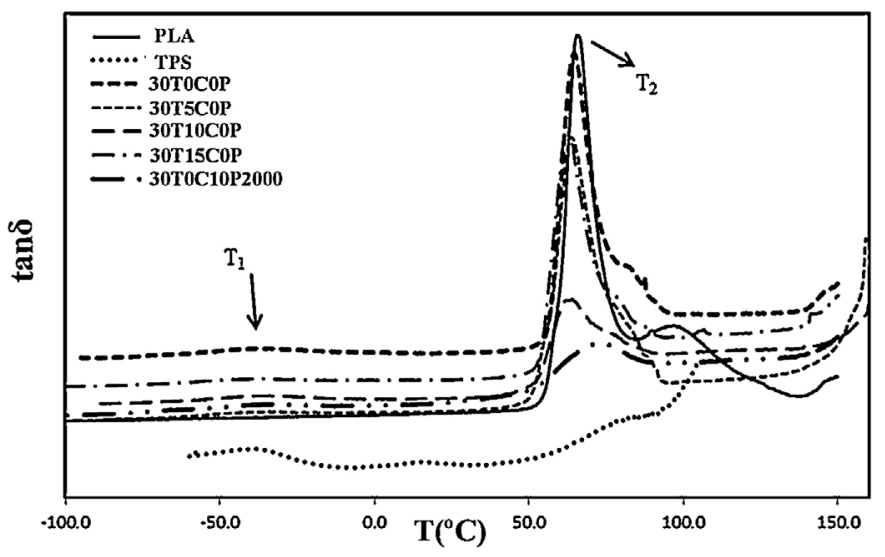

Fig. 5. $\tan \delta$ versus temperature of PLA, TPS and their blends.

Table 3

Transition temperatures of blends.

\begin{tabular}{lllc}
\hline Samples & $T_{1}\left({ }^{\circ} \mathrm{C}\right)$ & $T_{2}\left({ }^{\circ} \mathrm{C}\right)$ & $\Delta T$ \\
\hline PLA & $\mathrm{NS}^{\mathrm{a}}$ & 65.5 & - \\
TPS & -38.6 & $\mathrm{NS}$ & - \\
30T0COP & -42.6 & 63.9 & 106.5 \\
30T5COP & -39.1 & 63.4 & 102.5 \\
30T10COP & -34.4 & 61.2 & 95.6 \\
30T15COP & -39.1 & 62.2 & 101.3 \\
30T0C10P2000 & -32.9 & 71.8 & 104.7 \\
\hline
\end{tabular}

a Not seen.

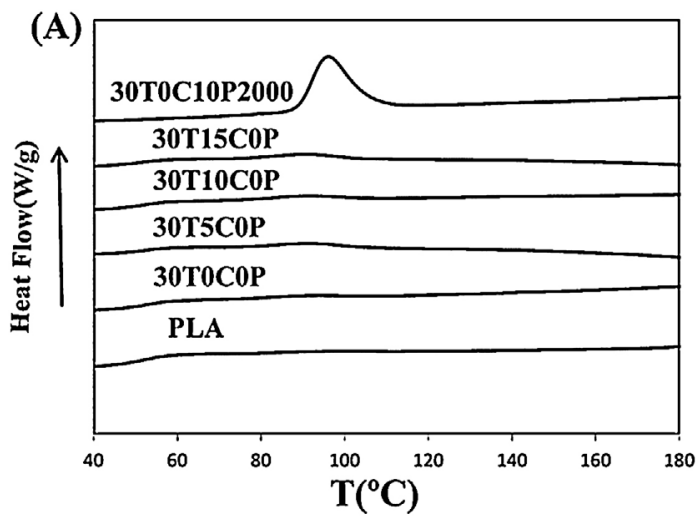

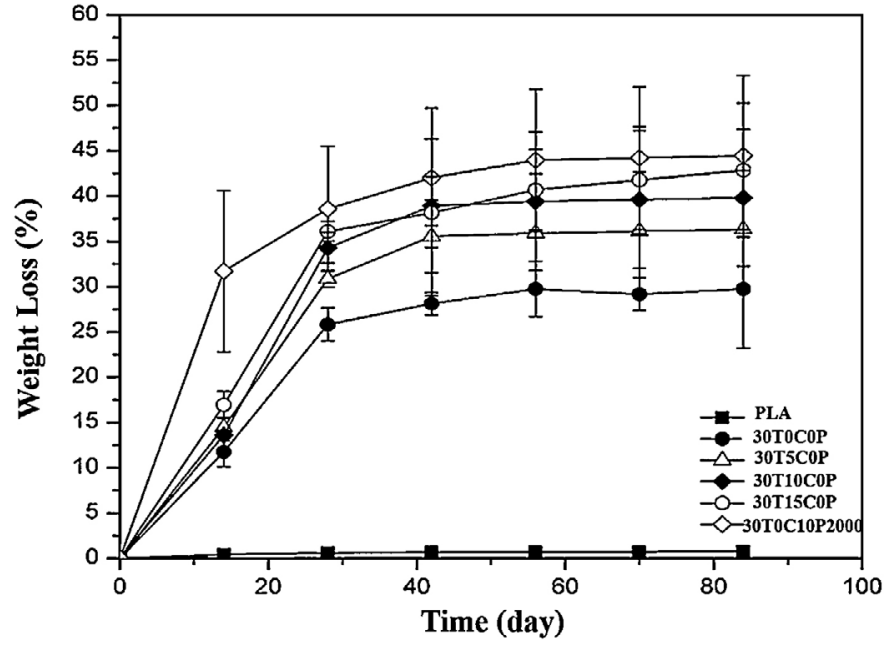

Fig. 7. Weight loss of samples.

binary blend (30T0COP). This reduction represents a further phase separation of glycerol from starch. Glycerol tends to migrate to the interface due to decrease of surface energy, leading to more reduction of $\tan \delta_{\max }$ (or glass transition temperature) for glycerol enriched phase. Migration of glycerol to the interface can also induce softening of the PLA chains with glycerol molecules, and decreases $T_{2}$ of the blends. This phenomenon was detected by DSC results which will be discussed later. Another

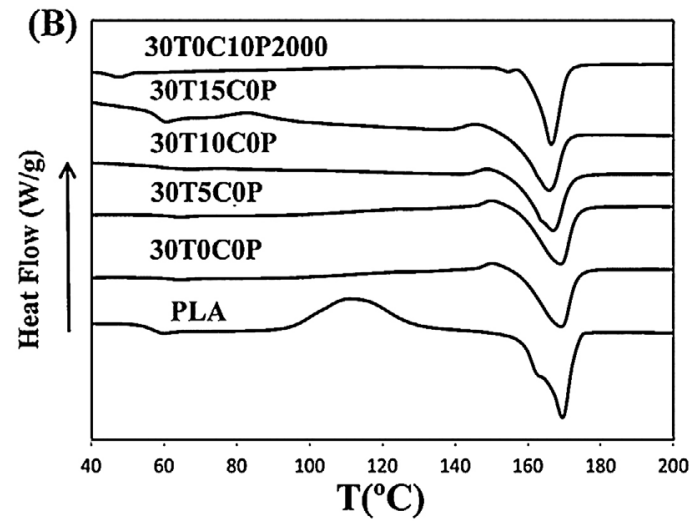

Fig. 6. DSC thermograms in (A) cooling step and (B) reheating step.

Table 4

Thermal analysis data for PLA and the respective blends with TPS and compatibilizer.

\begin{tabular}{|c|c|c|c|c|c|c|c|}
\hline Samples & $T_{m}\left({ }^{\circ} \mathrm{C}\right)$ & $T_{c}\left({ }^{\circ} \mathrm{C}\right)$ & $T_{\mathrm{CC}}\left({ }^{\circ} \mathrm{C}\right)$ & $\Delta H_{m}(\mathrm{j} / \mathrm{g})$ & $\Delta H_{c}(\mathrm{j} / \mathrm{g})$ & $\Delta H_{c c}(\mathrm{j} / \mathrm{g})$ & $\chi_{c}(\%)$ \\
\hline PLA & 169.8 & - & 111.2 & 45.17 & - & 42.26 & 48.56 \\
\hline 30ТОСОР & 166.44 & 91.61 & 94.41 & 35.61 & 1.24 & 23.91 & 54.70 \\
\hline 30Т5С0Р & 165.33 & 91.64 & 92.99 & 35.52 & 3.21 & 17.76 & 54.56 \\
\hline 30T10С0Р & 165.28 & 90.95 & 92.87 & 34.31 & 2.22 & 18.74 & 52.70 \\
\hline 30T15COP & 166.22 & 91.14 & 92.65 & 31.91 & 3.30 & 16.41 & 49.01 \\
\hline 30Т0С10Р2000 & 164.68 & 96.09 & - & 30.81 & 25.95 & - & 47.32 \\
\hline
\end{tabular}

Table 5

Mechanical properties of the samples.

\begin{tabular}{|c|c|c|c|}
\hline Samples & Tensile strength (MPa) & Elastic modulus (MPa) & Elongation at break (\%) \\
\hline PLA & $55 \pm 1.5$ & $2500 \pm 50.47$ & \\
\hline 30T0СОР & $18 \pm 1.02$ & $1701 \pm 86.56$ & $1.34 \pm 0.062$ \\
\hline 30Т5С0Р & $19 \pm 2.38$ & $1815 \pm 106.02$ & $1.42 \pm 0.1$ \\
\hline 30T10C0P & $21 \pm 2.96$ & $1631 \pm 73.57$ & $1.49 \pm 0.21$ \\
\hline 30T15COP & $18 \pm 1.37$ & $1563 \pm 44.91$ & $1.42 \pm 0.14$ \\
\hline 30Т0С10Р2000 & $14 \pm 2.12$ & $1595 \pm 76.55$ & $1.15 \pm 0.13$ \\
\hline
\end{tabular}


interesting point from DMTA analysis was the considerable increment in $T_{1}$ and $T_{2}$, because of polar nature of PEG molecules. It seems that, the main reason for this trend is the highly probable interaction between free PEG in compound with TPS molecules (30T0C10P2000). In other words, PEG molecules contribute to form of TPS-TPS branching or cross-linking rather than plasticizing effect on PLA.

\subsubsection{Crystallization}

Fig. $6 \mathrm{~A}$ and $\mathrm{B}$ shows the cooling and reheating steps of the DSC thermograms, and Table 4 summarizes the extracted data. Neat PLA did not show any crystallization peak in the cooling step possibly due to low crystallization rate (Fig. 6A). However, crystallization peaks appeared when TPS and compatibilizer were added to PLA. This behavior could be attributed to: the plasticizing effect of glycerol, which can migrate to the matrix blend and increase
PLA chain mobility and/or nucleating effect of dispersed TPS phase (Shi et al., 2011). The highest crystallization temperature $\left(96^{\circ} \mathrm{C}\right)$ was related to samples containing $10 \mathrm{phr}$ free PEG. This indicates that the dominant mechanism of facilitated crystallization is plasticizing of free PEG rather than nucleating effect of TPS. There are also peaks in the range of $92-111^{\circ} \mathrm{C}$ that are attributed to the cold crystallization in PLA (Fig. 6B). Cold crystallization usually occurs for PLA due to the low kinetic rate of crystallization, and the growth of crystals continues by thermal induced chain movement in this range of temperature. Cold crystallization temperature $\left(T_{\mathrm{CC}}\right)$ decreased with the increment of compatibilizer proportion; as such no $T_{\mathrm{CC}}$ was observed for the sample (30T0C10P2000). The presence of the compatibilizer could encourage the movement of polymeric chains into crystal cells in cooling step, and led to a decrease in $T_{\mathrm{CC}}$ in reheating step. Samples containing free PEG did not show any cold crystallization temperature which means the crystal structure had already been completed in the cooling step.
$\mathbf{A}$

a)PLA

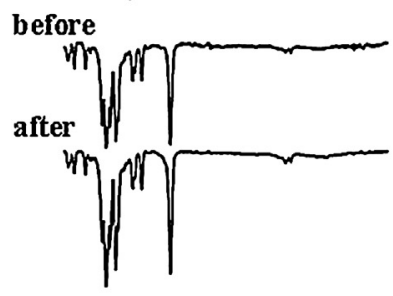

c) $30 \mathrm{~T} 5 \mathrm{E0P}$

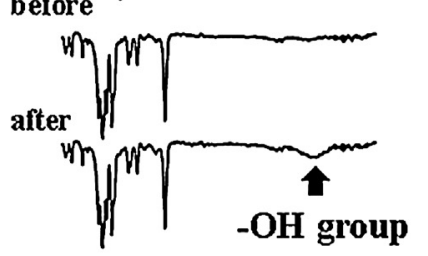

$500 \quad 1000 \quad 1500 \quad 2000 \quad 2500 \quad 3000 \quad 3500 \quad 4000 \quad 4500$
b)30T0C0P

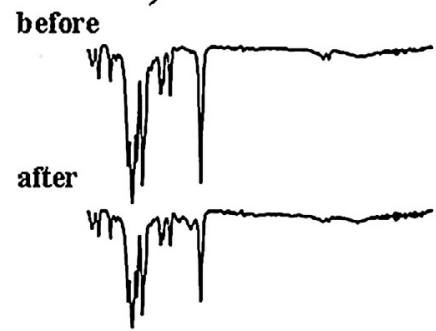

before
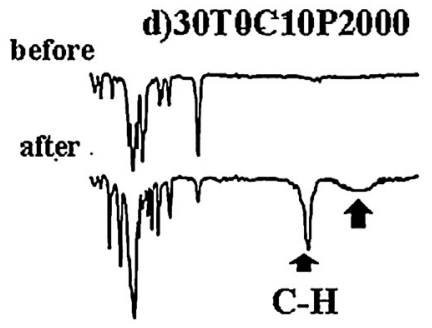

$500 \quad 1000 \quad 1500 \quad 2000 \quad 2500 \quad 3000 \quad 3500 \quad 4000 \quad 4500$
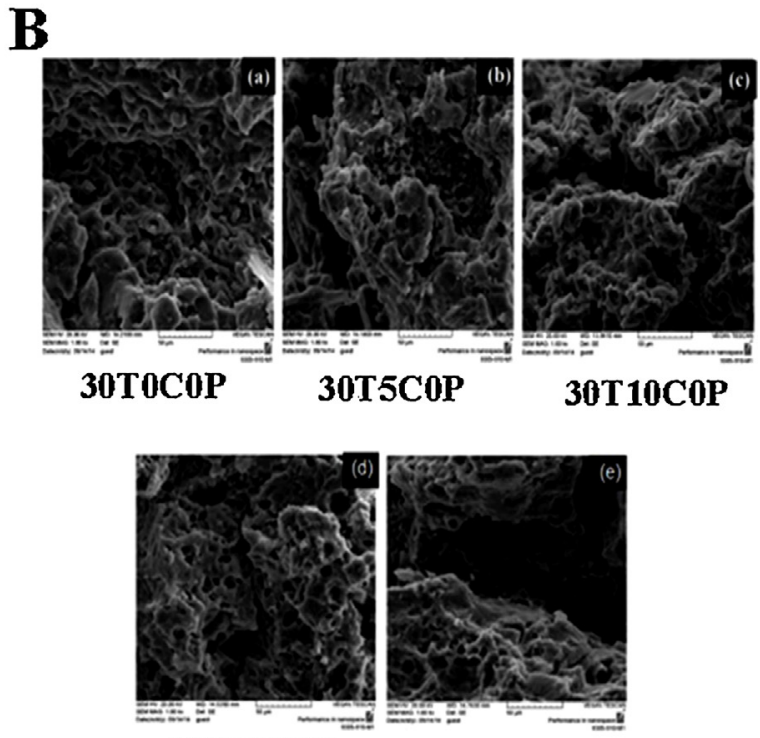

30T15C0P

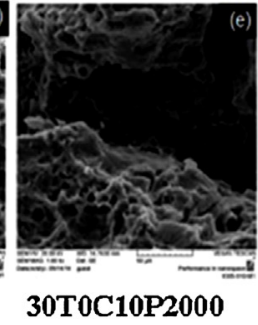

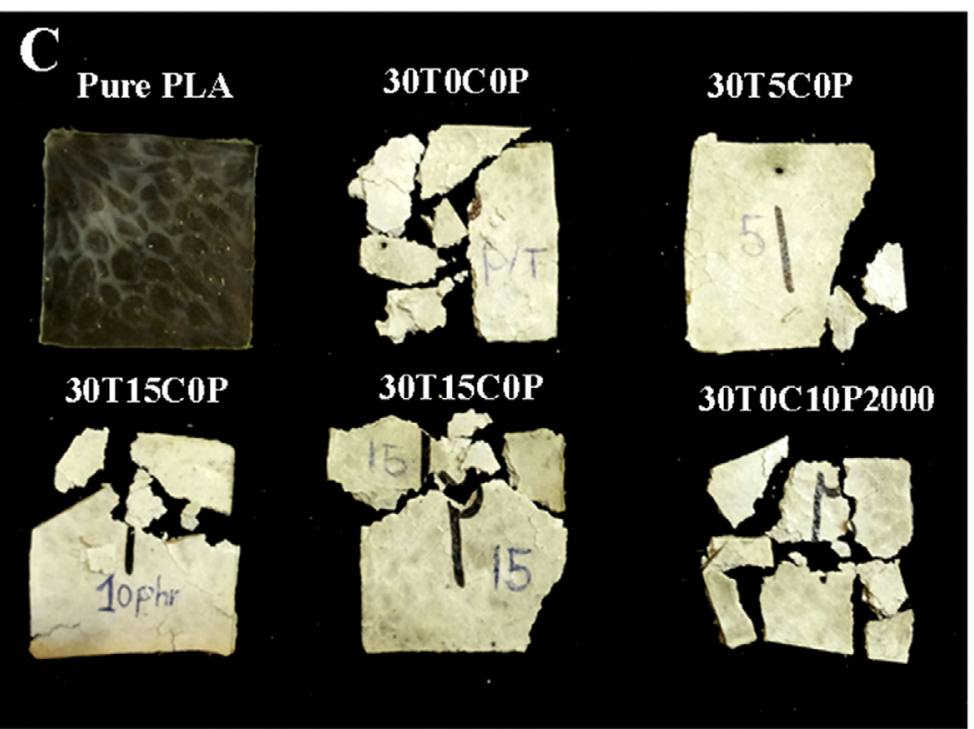

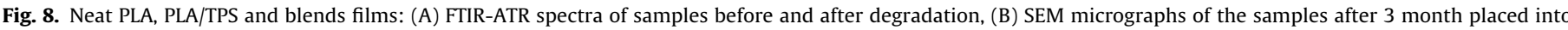
activated sludge and $(C)$ apparent variation of samples. 
The percentage of crystallization was calculated from the data obtained in the reheating step. The lowest $X_{c}$ is related to samples containing $10 \mathrm{phr}$ free PEG. This indicates a decrease in the present of crystallization compared to neat PLA in spite of an increase in crystallization rate. Melting behavior was also subjected to alteration upon blending of the neat PLA with compatibilizers. Neat PLA showed two melting peaks at $164^{\circ} \mathrm{C}$ and $157^{\circ} \mathrm{C}$ corresponding to $\alpha$ and $\beta$ crystal types, respectively (Auras, Lim, Selke, \& Tsuji, 2011). Whereas, $\beta$ peak disappeared upon blending of PLA with TPS and compatibilizer (Fig. 6). $\beta$ peak is usually formed in special condition of chain movement and stress field which it was eliminated by the presence of TPS (Auras et al., 2011). It seems, $\alpha$ crystal are more stable at the presence of these materials, $\beta$ crystals vanished due to limited chains movements.

\subsubsection{Mechanical properties}

Tensile properties of the samples are depicted in Table 5. Since the tensile strength of TPS is much lower than that of pure PLA, the tensile strengths of all blends were lower than that of pure PLA, and followed the "rule of mixtures". However, in the 30TOCOP sample, tensile strength significantly decreased, and showed a negative deviation from the rule of mixtures due to the incompatibility between the matrix and dispersed phase. In addition, tensile strength improved in the presence of compatibilizer, and led to a positive deviation from the rule of mixtures. This is mainly because of enhanced interfacial adhesion as well as delayed formation of craze and micro-cracks. This trend was observed up to $10 \mathrm{phr}$ of compatibilizer, and samples with higher content of compatibilizer (15 phr, 30T15COP sample) showed lower tensile strength because of phase separation.

Consideration the fact that the modulus of TPS is lower than that of neat PLA, because of large amount of plasticizer and loss of crystalline parts, it is expected that addition of TPS to PLA reduces the elastic modulus of the systems (Wang, Yu, Chang, \& Ma, 2007). Moreover, the reduction of elastic modulus in the presence of compatibilizer is a proof of gelatinization and absence of starch granules. Otherwise, these granules can increase the tensile modulus as solid fillers.

Elongations at break values for all compounds were small, and the samples cracked up to $1.49 \%$ for the best case. This is because of the brittleness nature of PLA and starch. Reduction of elongation at break by addition of more than $10 \mathrm{wt}$.\% of TPS is previously reported (Shin, Jang, \& Kim, 2011). The trend of elongation at break was to some extent similar to that of tensile strength upon addition of compatibilizer. Here, the reason of decline due to compatibilizer is the phase separation that acts as defect sites, and reduces the elongation at break.

\subsubsection{Biodegradability}

Biodegradability was evaluated by various methods including weight loss, FTIR-ATR analysis and morphology. Fig. 7 shows the weight loss of samples in compost testing. Neat PLA shows minimal weight loss rate with less than $0.35 \%$ after 90 days. This is explained by highly hydrophobic structure and steric shielding effect of the methyl side groups of the PLA (Vroman \& Tighzert, 2009). On the other hand, pure TPS was quickly decomposed in less than a month (data are not shown due to rapid degradation). Addition of TPS to the samples increased hydrophilic nature of the compounds and destroyed the crystalline structure of PLA. This facilitated microorganism's penetration into the blends, and increased biodegradation up to $42.61 \%$ of the initial weight after 3 months.

It seems the biodegradation kinetics is composed of two stages: the first stage is rapid because of high concentration of starch and diffusion of glycerol (as a small molecule) to the surface and consumption by microorganisms. On the other hand, decomposition rate is slow in the second stage where the remained TPS particles surrounded by poly(lactic acid), hampers permeability to microorganisms or enzyme (Tena-Salcido, Rodríguez-González, Méndez-Hernández, \& Contreras-Esquivel, 2008). We observed no significant alteration of weight loss at the presence of compatibilizer. This is because of constant concentration of the TPS in all samples which plays the main role in the initiation and development of degradation. The minor differences among samples containing compatibilizer can be referred to biodegradability nature of the compatibilizers.

Fig. 8A shows the FTIR-ATR spectra of the neat PLA and blend samples (b) 30T0COP; (c) 30T5COP; (d) 30T0C10P200 before and after degradation. In all compounds, the characteristic peaks in the range of $3000-3600 \mathrm{~cm}^{-1}$ corresponding to hydroxyl groups stretching of TPS disappeared after degradation. The main characteristic peak of PLA $\left(1750 \mathrm{~cm}^{-1}\right.$ for Carbonyl group) did not change significantly. It means, the main degradation occurred in the TPS phase, and related peaks disappeared after full degradation of this phase.

The morphologies of samples after 3 months degradation in compost were investigated by SEM (shown in Fig. 8B). The surfaces of samples were smooth before degradation. After degradation, we observed several holes and cracks as a result of penetration of microorganisms on the surface of samples which is the criterion for sample decomposition. In other hand, the surface of samples was eroded and became rough.

The changes in the appearance of samples after 3 months burial in compost are presented in Fig. 8C. As expected, there was no considerable change in neat PLA while in other samples the size of the samples became smaller and some parts of them decomposed completely.

\section{Conclusion}

This work is motivated by current researches in the development of PLA applications as a biodegradable polymer. In this study, a new compatibilizer based on maleic anhydride grafted polyethylene glycol grafted starch (mPEG-g-St) was synthesized to improve the compatibility of the poly(lactic acid)/thermoplastic starch blends. To study the efficiency of synthesized compatibilizer, several blends samples were prepared based on PLA/thermoplastic starch and their morphology, dynamic-mechanical behavior, crystallization, mechanical properties and biodegradability were studied. Following results can be drawn from this work:

- A new compatibilizer for PLA/TPS blend was synthesized and characterized by FTIR, DMTA and back titration methods. The FTIR as a powerful method confirmed the creation of new peaks which confirmed the occurrence of designed reactions. Our imagination of the structure of the obtained compabilizer is a starch cored structure with many connections to m-PEG chains. Regarding to this structure, there are pending chains including free end carboxylic acid groups which can interact with active groups of TPS and PLA phases.

- Morphological studies using SEM micrographs showed that the distribution of dispersed particle size (starch) in blend samples is more homogeny and narrower for the samples containing compatibilizer.

- DMTA analysis showed a decrease in the differences between $\tan \delta_{\max }$ of the two phases for samples containing compatibilizer.

- Crystallization behavior of the PLA was affected by compatibilizer and influence the final properties. Cold crystallization temperature $\left(T_{\mathrm{CC}}\right)$ decreased with the increase of compatibilizer ratio, and no $T_{\mathrm{CC}}$ was observed for samples (30T0C10P2000) which implies to complete crystallization on the cooling step. 
- The presence of compatibilizer cause to positive deviation from the rule of mixture for tensile properties of the blend samples which can be a good indication for compatibilizer efficiency.

- Compatibilizer did not influence the biodegradability behavior.

\section{References}

Auras, R., Harte, B., \& Selke, S. (2004). An overview of polylactides as packaging materials. Macromolecular Bioscience, 4(9), 835-864.

Auras, R. A., Lim, L. T., Selke, S. E., \& Tsuji, H. (2011). Poly(lactic acid): Synthesis, structures, properties, processing, and applications. John Wiley \& Sons.

Chapleau, N., Huneault, M. A., \& Li, H. (2007). Biaxial orientation of polylactide/thermoplastic starch blends. International Polymer Processing (Special issue on bio based polymers), 22(5), 1-8.

Da Róz, A. L., Carvalho, A. J. F., Gandini, A., \& Curvelo, A. A. S. (2006). The effect of plasticizers on the thermoplastic starch compositions obtained by melt processing. Carbohydrate Polymers, 63, 417-424.

Ferrarezi, M. M. F., de Oliveira Taipina, M., da Silva, L. C. E., \& do Carmo Gonçalves, M. (2013). Poly(ethylene glycol) as a compatibilizer for poly(lactic acid)/thermoplastic starch blends. Journal of Polymers and the Environment, 21 $151-159$.

Garlotta, D. (2002). A literature review of poly(lactic acid). Journal of Polymers and the Environment, 9(2), 63-84.

Hulleman, S. H. D., Janssen, F. H. P., \& Feil, H. (1998). The role of water during plasticization of native starches. Polymer, 39(10), 2043-2048.

Huneault, M. A., \& Li, H. (2007). Morphology and properties of compatibilized polylactide/thermoplastic starchblends. Polymer, 48(1), 270-280.

Jamshidian, M., Tehrany, E. A., Imran, M., Jacquot, M., \& Desobry, S. (2010). Poly-lactic acid: Production, applications, nanocomposites, and release studies. Comprehensive Reviews in Food Science and Food Safety, 9(5), 552-571.

Karagoz, S., \& Ozkoc, G. (2013). Effects of a diisocyanate compatibilizer on the properties of citric acid modified thermoplastic starch/poly(lactic acid) blends. Polymer Engineering \& Science, 53(10), 2183-2193.

Ke, T., \& Sun, X. S. (2003). Thermal and mechanical properties of poly(lactic acid)/starch/methylene diphenyl diisocyanate blending with triethyl citrate. Journal of Applied Polymer Science, 88, 2947-2955.

Kim, S. H., Chin, I. J., Yoon, J. S., \& Jung, J. S. (1998). Mechanical properties of biodegradable blends of poly(L-lactic acid) and starch. Korea Polymer Journal, 6(5), 422-427

Leja, K., \& Lewandowicz, G. (2010). Polymer biodegradation and biodegradable polymers - a review. Journal of Enviromental Studies, 19(2), 255-266.

Li, H., \& Huneault, M. A. (2011). Comparison of sorbitol and glycerol as plasticizers for thermoplastic starch in TPS/PLA blends. Journal of Applied Polymer Science, 119(4), 2439-2448.

Lourdin, D., Bizot, H., \& Colonna, P. (1997). “Antiplasticization” in starch glycerol films? Journal of Applied Polymer Science, 63(8), 1047-1053.

Lu, D. R., Xiao, C. M., \& Xu, S. J. (2009). Starch-based completely biodegradable polymer materials. Express Polymer Letters, 3(6), 366-375.

Ma, X. F., Yu, J. G., \& Wan, J. J. (2006). Urea and ethanolamine as a mixed plasticizer for thermoplastic starch. Carbohydrate Polymers, 64, 267-273.

Orozco, V. H., Brostow, W., Chonkaew, W., \& Lopez, B. L. (2009). Preparation and characterization of poly(lactic acid)-g-maleic anhydride + starch blends. Macromolecular Symposia, 277(1), 69-80.

Ping, X., Kejian, W., Mingyin, J., \& Meijuan, Y. (2013). Biodegradation and mechanical property of polylactic acid/thermoplastic starch blends with poly(ethylene glycol). Journal of Wuhan University of Technology-Materials Science, 28(1), 157-162.

Poutanen, K., \& Forssell, P. (1996). Modification of starch properties with plasticizers. Trends in Polymer Science, 4, 128-132.
Schwach, E., \& Avérous, L. (2004). Starch-based biodegradable blends: Morphology and interface properties. Polymer International, 53(12), 2115-2124.

Schwach, E., Six, J. L., \& Avérous, L. (2008). Biodegradable blends based on starch and poly(lactic acid): Comparison of different strategies and estimate of compatibilization. Journal of Polymers and the Environment, 16(4), 286-297.

Shin, B. Y., Jang, S. H., \& Kim, B. S. (2011). Thermal, morphological, and mechanical properties of biobased and biodegradable blends of poly(lactic acid) and chemically modified thermoplastic starch. Polymer Engineering \&'Science, 51, 826-834.

Shi, Q., Chen, C., Gao, L., Jiao, L., Xu, H., \& Guo, W. (2011). Physical and degradation properties of binary or ternary blends composed of poly(lactic acid), thermoplastic starch and GMA grafted POE. Polymer Degradation and Stability, 96(1), 175-182.

Shi, R., Zhang, Z. Z., Liu, Q. Y., Han, Y. M., Zhang, L. Q., Chen, D. F., et al. (2007). Characterization of citric acid/glycerol co-plasticized thermoplastic starch prepared by melt blending. Carbohydrate Polymers, 69, 748-755.

Shogren, R. L., Swanson, C. L., \& Thompson, A. R. (1992). Extrudates of cornstarch with urea and glycols: Structure/mechanical property relations. Starch-Stärke, 44(9), 335-338.

Siracusa, V., Rocculi, P., Romani, S., \& Rosa, M. D. (2008). Biodegradable polymers for foodpackaging: A review. Trends in Food Science \& Technology, 19(12), 634-643.

Stepto, R. F. T. (2003). The processing of starch as a thermoplastic. Macromolecular Symposia, 201(1), 203-212.

Tachaphiboonsap, S., \& Jarukumjorn, K. (2013). Toughness and compatibility improvement of thermoplastic starch/poly(lactic acid) blends. Advanced Materials Research, 747, 67-71.

Tang, X., Alavi, S., \& Herald, T. J. (2008). Effects of plasticizers on the structure and properties of starch-clay nanocomposite films. Carbohydrate Polymers, 74(3), $552-558$.

Teixeira, E. D. M., Curvelo, A. A., Corrêa, A. C., Marconcini, J. M., Glenn, G. M., \& Mattoso, L. H. (2012). Properties of thermoplastic starch from cassava bagasse and cassava starch and their blends with poly(lactic acid). Industrial Crops and Products, 37(1), 61-68.

Teixeira, E. M., Da Roz, A. L., Carvalho, A. J. F., \& Curvelo, A. A. S. (2007). The effect of glycerol/sugar/water and sugar/water mixtures on the plasticization of thermoplastic cassava starch. Carbohydrate Polymers, 69, 619-624.

Tena-Salcido, C. S., Rodríguez-González, F. J., Méndez-Hernández, M. L., \& Contreras-Esquivel, J. C. (2008). Effect of morphology on the biodegradation of thermoplastic starch in LDPE/TPS blends. Polymer Bulletin, 60(5), $677-688$

Tester, R. F., \& Karkalas, J. (2001). The effects of environmental conditions on the structural features and physico-chemical properties of starches. Starch-Stärke, 53(10), 513-519.

Vroman, I., \& Tighzert, L. (2009). Biodegradable polymers. Materials, 2(2), 307-344.

Wang, N., Yu, J., Chang, P. R., \& Ma, X. (2007). Influence of citric acid on the properties of glycerol-plasticized dry starch (DTPS) and DTPS/poly(lactic acid) blends. Starch-Stärke, 59, 409-417.

Wang, N., Yu, J., \& Ma, X. (2007). Preparation and characterization of thermoplastic starch/PLA blends by one-step reactive extrusion. Polymer International, 56, 1440-1447.

Wootthikanokkhan, J., Kasemwananimit, P., Sombatsompop, N., Kositchaiyong, A. Isarankurana Ayutthaya, S., \& Kaabbuathong, N. (2012). Preparation of modified starch-grafted poly(lactic acid) and a study on compatibilizing efficacy of the copolymers in poly(lactic acid)/thermoplastic starch blends. Journal of Applied Polymer Science, 126(1), 389-396.

Zhang, J. F., \& Sun, X. (2004). Mechanical properties of poly(lactic acid)/starch composites compatibilized by maleic anhydride. Biomacromolecules, 5(4), 1446-1451. 